\title{
EXPERIMENTAL STUDY OF COAXIAL LASER CLADDING OF TOOL STEEL
}

\author{
Sergejs Locs ${ }^{1,2}$, Irina Boiko ${ }^{1}$, Armands Leitans ${ }^{1}$, Pavels Drozdovs ${ }^{2}$ \\ ${ }^{1}$ Riga Technical University, Latvia; ${ }^{2}$ Daugavpils University, Latvia \\ irina.boiko@rtu.lv, sergey.loch@gmail.com
}

\begin{abstract}
This paper was devoted to the experimental study of coaxial laser cladding during repairing of the parts made from tool steel such as boring tools, forming rolls, stamping punches, dies, etc. The goal of the study was achievement of the possibly best quality of cladded layers due to high demands of wear resistance and durability of the mentioned parts. The experimental part of the study was based on varying of technological parameters of the laser cladding process. The mechanical properties of the achieved cladded coatings were evaluated by hardness measures and wear test using a ball-on-disc type tribometer according to the tribology standards ASTM G99, DIN 50324. The friction coefficient and wear rate of a counter-body was determined at $3 \mathrm{~N}$ load at $0.05 \mathrm{~m} \cdot \mathrm{s}^{-1}$ linear speed. The result analysis of the experimental study and testing of the created coatings allow concluding that the goal of the study was achieved, i.e. the combination of the technological parameters, which guarantee high functional properties of the coating, was found. Additionally, the isotropy of the tested properties was revealed.
\end{abstract}

Keywords: laser cladding, tool steel, coating, hardness, coefficient of friction, wear, ANOVA.

\section{Introduction}

Laser cladding (LC) is a progressive surface engineering technology that can be used to improve mechanical and tribological surface properties of metallic components by creating functional coatings herein providing a combination of strong metallurgical bond with minimal thermal distortion of the product $[1 ; 2]$. As a result of many advantages in comparison to thermal spraying and welding processes LC is successfully applied for refurbishment and repair of high value machine components and tools (turbines, dies, punches, press molds etc.), and it is also applied in the rapid manufacturing industry $[3 ; 4]$.

Investigation of the LC process is rather complicated due to numerous amounts of input parameters and their interactions. The main of them are laser power, laser scanning speed, focus plane distance, laser beam characteristics, continuous or pulsed wave light emission, type of the filler material and its feed rate, amount and sort of shielding and carrier gas, also the physical effects of the process (thermal distribution, fluid flow, phase transformation etc.) [5]. Variety of input parameters may have different effect on the process response in form of geometry, metallurgical, mechanical, chemical and physical properties, which in its order characterizes overall quality of the coating. Nowadays, finite elements methods (FEM) are appearing as a novel approach for investigation of the process and are actively used for analysis of laser clad geometry, dilution, temperature field and residual stresses [6;7]. However, there are plenty of side effects, which are difficult to include into the model and this fact leads to serious deviation from the experimental results. Wherein statistical analysis methods are good alternative to study relationships between the process parameters and any sought characteristics. Several studies were carried out for investigation of the process parameter influence onto the clads quality by characterization of the microstructure and mechanical properties in tool steel repair applications, where however absence of defects has been detected (presence of cracks and pores) [8-10]. Therefore, determination of optimal LC parameters as well as use of appropriate processing strategy, which allows minimize the number of defects, is always an actual issue [11].

LC coating is formed by applying successive partly overlapping of single cladding tracks. Machinery components made as a rotation body such as pinion-shafts, forming rolls, boring tools and stamping pins technologically could be laser cladded by two strategies, namely by cladding longitudinal to the rotary direction (Fig. 1a) or transverse to it (Fig. 1b). However, surface finish after laser cladding (cylindrical grinding) is performed only longitudinally to the rotary direction. For this reason the primary goal of the present research was investigation of the relation between the direction of laser cladding and the direction of mechanical grinding of the coatings in case when the samples have been grinded in a longitudinal way to the cladded tracks and transverse to them. The secondary goal was to define the appropriate process parameter set to achieve coating of good quality. 
a)

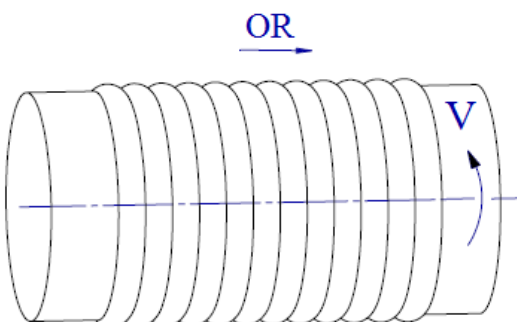

b)

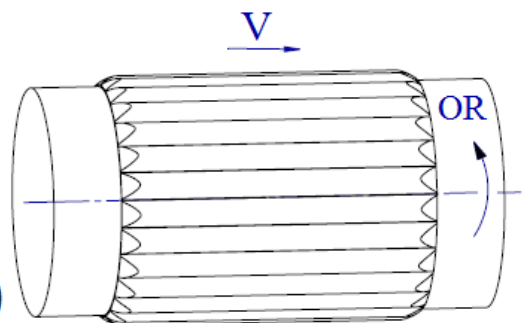

Fig. 1. Methods of laser cladding of cylindrical surface, a - longitudinal to rotary direction, b - transverse to rotary direction: $\mathrm{V}$ - direction of laser scanning; OR - direction of overlap

\section{Materials and experimental details}

The experimental work was carried out using the precise laser cladding system, which consists of the industrial 6 axis robot KR30HA, 2 axis DKP-400 positioner $(K u k a), 1 \mathrm{~kW} \mathrm{Yb-fiber} \mathrm{laser} \mathrm{YLR}$ 1000 (IPG Laser) with $100 \mu \mathrm{m}$ optical fiber delivering laser beam to the optical system of coaxial powder supplying cladding head WT03 (Permanova Lasersystem). Ytterbium laser emits a light beam with a wavelength of $1070 \mathrm{~nm}$. The optical system has $200 \mathrm{~mm}$ collimation lens focus and $200 \mathrm{~mm}$ focal length of the focusing lens, which results in the laser beam spot size in a focus plane of about $100 \mu \mathrm{m}$ with a Gaussian distribution of energy density. Powder feeding performed with the powder feeder TWIN-10-C (Sulzer Metco), where argon was used as a carrier gas and as a shielding gas to prevent oxidation of the powder and molten pool. The laser cladding equipment is presented in Fig. 2.

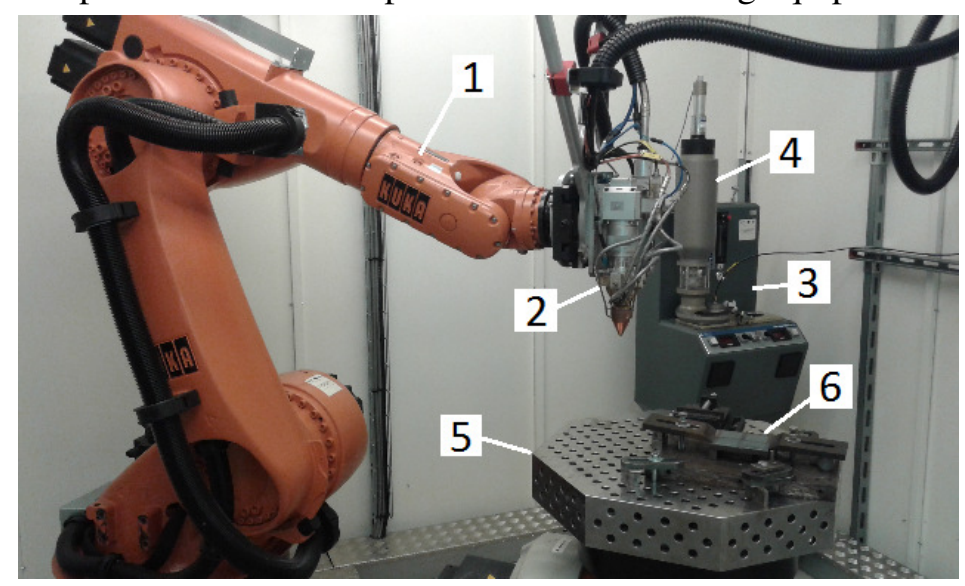

Fig. 2. Laser cladding equipment: 1 - industrial robot; 2 - cladding tool; 3 - powder feeder; 4 - powder insert; 5 - table of positioner; 6 - workpiece

Laser cladding in this study was carried out on the top surface of high carbon wear resistant steel (DIN 66Mn4) substrates with the plate dimensions of 100x100x10 mm. All samples were surfaceground before treatment. The coating material was globe-shaped high speed steel powder (AISI M2) with the particle size 53-150 $\mu \mathrm{m}$. Figure 3 presents a micrograph of powder morphology under Scanning Electron Microscope (SEM). The chemical composition of the materials is presented in Table 1.

Chemical composition of powder AISI M2 (1) and substrates DIN 66Mn4 (2) wt. \%

\begin{tabular}{|c|c|c|c|c|c|c|c|c|c|c|}
\hline No & $\mathbf{C}$ & $\mathbf{M n}$ & $\mathbf{S i}$ & $\mathbf{M o}$ & $\mathbf{C r}$ & $\mathbf{V}$ & $\mathbf{W}$ & $\mathbf{N i}$ & $\mathbf{C u}$ & $\mathbf{C o}$ \\
\hline 1 & $0.85-1.05$ & $0.20-0.40$ & $0.20-0.40$ & $4.50-5.50$ & $3.75-4.50$ & $1.60-2.20$ & $5.50-6.80$ & $<0.60$ & $<0.25$ & $<0.50$ \\
\hline 2 & $0.62-0.70$ & $0.90-1.20$ & $0.17-0.37$ & - & $<0.25$ & - & - & $<0.25$ & $<0.20$ & - \\
\hline
\end{tabular}

The highlighted parameters for variation were laser cladding tracks overlap the ratio $(O R)(50 \%$ and $35 \%)$, cladding speed $\left(0.01 \mathrm{~m} \cdot \mathrm{s}^{-1}\right.$ and $\left.0.02 \mathrm{~m} \cdot \mathrm{s}^{-1}\right)$ and laser beam focus plane distance $(f=-2 \mathrm{~mm}$ and $f=+2 \mathrm{~mm}$ ). The thickness of the achieved coating and mechanical properties such as hardness and the coefficient of friction were evaluated on each stage of the research. 


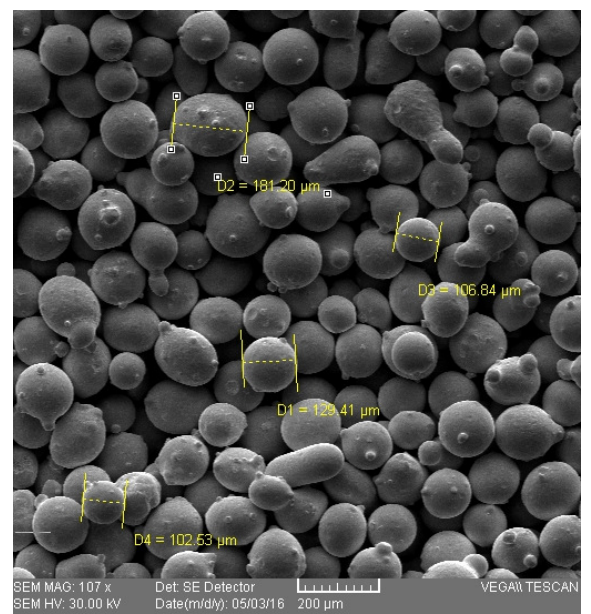

Fig. 3. SEM micrograph of M2 powder morphology

With the aim to establish interaction of the three parameters (overlap ratio, scanning speed and laser beam focus plane distance) onto the coating quality and properties the experimental research was carried out using experimental design (DOE) in form of two level full factorial design $2^{3}$ (Table 2). During the process the laser beam was directed to the surface of the sample with stand-off distance $8 \mathrm{~mm}$ from the nozzle end. The following process parameters were fixed to operate: laser power $1000 \mathrm{~W}$; carrier gas flow (Ar) $51 \cdot \mathrm{min}^{-1}$; shielding gas flow (Ar) $161 \cdot \mathrm{min}^{-1}$; powder mass feed rate $7 \mathrm{~g} \cdot \mathrm{min}^{-1}$. In sum 16 coatings (with area of $45 \times 45 \mathrm{~mm}$ ) by two groups $(2 \times 8)$ were deposited, which were produced by successive laser scanning of the surface at a multiple combination of parameters (Table 2). In order to investigate the relationship between the properties of the coating and the direction of mechanical grinding, after deposition the samples with produced coatings were divided into two groups for surface grinding in two different directions: along and across laser cladding tracks.

Factors and levels of variation

\begin{tabular}{|c|c|c|c|c|}
\hline \multirow{2}{*}{ Factors } & \multirow{2}{*}{ Designation } & \multicolumn{3}{|c|}{ Levels } \\
\cline { 3 - 5 } & & $\begin{array}{c}\text { Upper } \\
(+\mathbf{1})\end{array}$ & $\begin{array}{c}\text { Nominal } \\
(\mathbf{0})\end{array}$ & $\begin{array}{c}\text { Lower } \\
(\mathbf{- 1})\end{array}$ \\
\hline Overlap ratio, \% & $O R$ & 50 & 43 & 35 \\
\hline Scanning speed, $\mathrm{m} \cdot \mathrm{s}^{-1}$ & $V$ & 0.02 & 0.015 & 0.01 \\
\hline Focus disposition, $\mathrm{mm}$ & $f$ & -2 & 0 & +2 \\
\hline
\end{tabular}

Hardness measurements were performed with the PROCEQ Equostat 3 portable hardness measurement device. Eight evenly distributed measurements were performed for each sample. During data processing the lowest and the highest measurement values were discarded and the final hardness value calculated as average out of the rest six measurements. Hardness was measured in accordance with the standard DIN 50157.

The coefficient of friction was measured in accordance with the ASTM G99 and DIN 50324 tribology standard using the CSM Instruments "ball-on-disc" tribometer, while the tested specimen was used as a disc, but a high-strength steel ball (surface hardness ca. 62 HRC) was used as a counterbody. Experimental settings for the tribological research were the following: diameter of the ball: $6 \mathrm{~mm}$; material of the ball: 100Cr6 (DIN EN ISO 683-17); ball contact radius: $3 \mathrm{~mm}$; normal load: $3 \mathrm{~N}$; sliding speed: $0.05 \mathrm{~m} \cdot \mathrm{s}^{-1}$; room temperature: $20 \pm 1{ }^{\circ} \mathrm{C}$, without lubrication. The tests were performed by three radiuses of rotation on each coating, namely $3 \mathrm{~mm}, 6 \mathrm{~mm}$ and $9 \mathrm{~mm}$ with the sliding distance of 500 laps. After performing of the friction coefficient measurements, wear rate of the ball was determined by measuring of the wear area using the digital microscope Hirox KH-7700.

\section{Results and discussion}

The quality of the produced coatings was evaluated by two stages. The first one includes measurements of the coating thickness and visual examination of cladded surfaces before post- 
machining and after it. The created coatings were finished in two different directions: one group (a half) of 16 coatings was flat grinded in longitudinal direction to the cladded tracks; the second group was flat grinded in transverse direction. The second stage includes analysis of the following properties: hardness and the coefficient of friction. With the aim to investigate significance of the relationship between the process parameters and the chosen responses: such as coating thickness, hardness and the coefficient of friction analysis of variance (ANOVA) was used. The analysis was performed with a confidence level of $95 \%$ ( $p$-value of 0.05 ).

\section{Visual examination and thickness of coatings}

Figure 4 shows images of coating surfaces in as-clad condition relative to the combination set of the parameters (Table 3). By visual observation of the coating surfaces it was noticed that all of them have a good fusion with the base material without any surface defects as pores, crack or exfoliations.

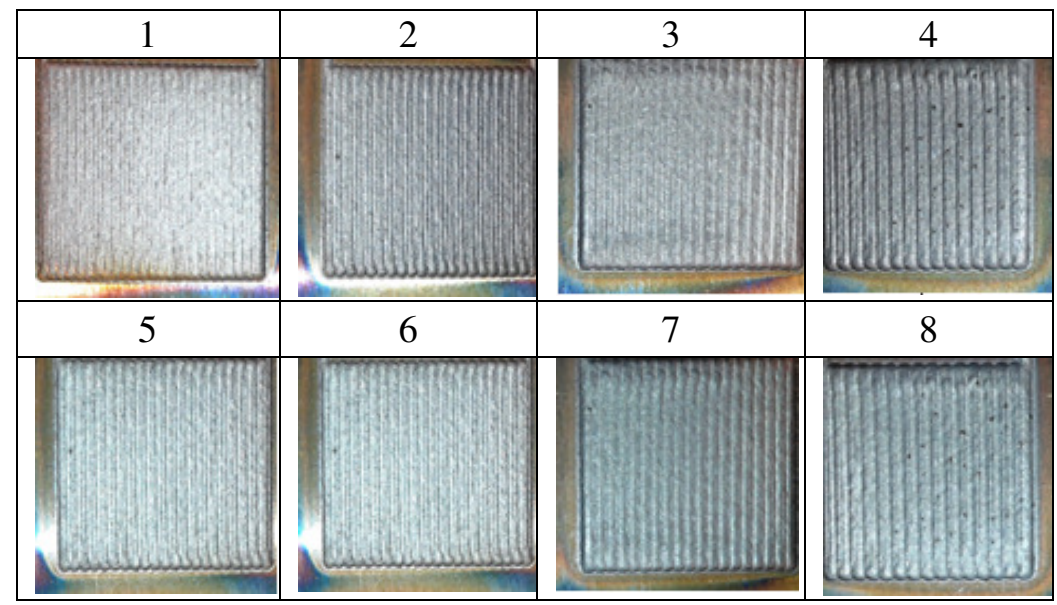

Fig. 4. Coating surfaces in as-clad condition

As it can be seen in Figure 4, as a result of varying of the parameters the density of the surface waviness changes. The most effect to this had overlap of clad tracks and laser scanning speed. For the following tests the coatings were grinded in two different ways: in longitudinal and transverse directions, relatively to laser cladding tracks. The average surface roughness after treatment in the longitudinal direction was $\mathrm{Sa}=0.55 \mu \mathrm{m}$ (arithmetical mean height of surface) and for the transverse direction it was $\mathrm{Sa}=0.61 \mu \mathrm{m}$. After finishing the coatings, it was noticed that a part of coatings had good surface quality without any visible defects (Fig. 5a), however a part of the coatings had porous surfaces (Fig. 5b).

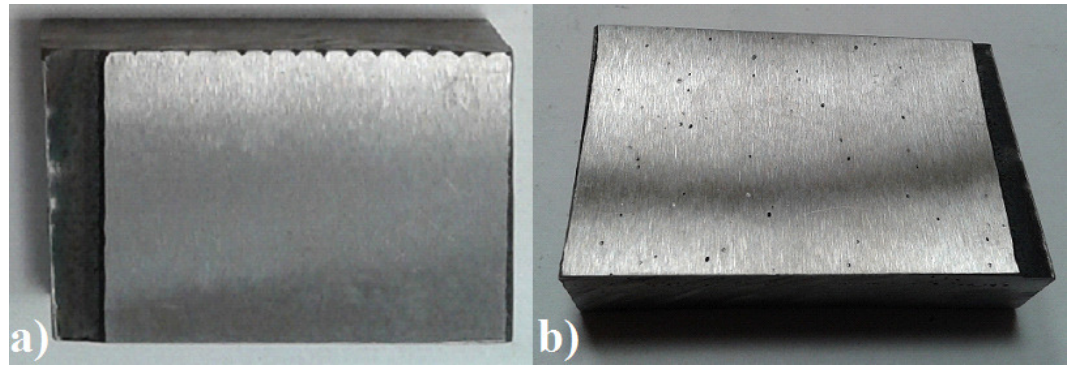

Fig. 5. Coating surfaces after flat grinding

By examination of all finished surfaces it was determined that porosity was typical for the lowest scanning speed and defocus at minus direction, which relates to coatings number 3 and 4 and had the identical nature in both groups of the grinded surfaces. Table 3 presents the used plan of DOE for two groups of samples with coatings, also their average thickness measures in as-clad condition and assessment of the grinded surface quality.

The thickness of as-clad coatings varied from about 0.4 to $1 \mathrm{~mm}$, the minimal value as it has been expected corresponds to the highest scanning speed and for the largest step of overlap. Figure 6 presents coatings thickness distribution relative to the combination set of the parameters. 
Experimental design matrix, thickness and quality assessment

\begin{tabular}{|c|c|c|c|c|c|c|}
\hline \multicolumn{2}{|c|}{$\begin{array}{c}\text { Coating No/Set } \\
\text { of parameters }\end{array}$} & $\boldsymbol{O R}, \boldsymbol{\%}$ & $\begin{array}{c}\text { Speed, } \\
\mathbf{m} \cdot \mathbf{s}^{-\mathbf{1}}\end{array}$ & $\begin{array}{c}\text { Defocus, } \\
\mathbf{m m}\end{array}$ & $\begin{array}{c}\text { Coating } \\
\text { height, } \mathbf{m m}\end{array}$ & $\begin{array}{c}\text { Surface } \\
\text { quality }\end{array}$ \\
\hline 1.1 & 2.1 & 50 & 0.02 & -2 & 0.6 & good \\
\hline 1.2 & 2.2 & 35 & 0.02 & -2 & 0.4 & good \\
\hline 1.3 & 2.3 & 50 & 0.01 & -2 & 1.0 & pores \\
\hline 1.4 & 2.4 & 35 & 0.01 & -2 & 0.8 & pores \\
\hline 1.5 & 2.5 & 50 & 0.02 & 2 & 0.5 & good \\
\hline 1.6 & 2.6 & 35 & 0.02 & 2 & 0.4 & good \\
\hline 1.7 & 2.7 & 50 & 0.01 & 2 & 0.8 & good \\
\hline 1.8 & 2.8 & 35 & 0.01 & 2 & 0.7 & good \\
\hline
\end{tabular}

The largest values of thickness particularly match the lowest scanning speed, which corresponds to the parameter set No. 3; 4; 7 and 8. Meanwhile, defocusing the laser beam to minus direction leads to appearance of excessive porosity (coatings No. 3 and 4). Table 4 represents ANOVA for the coating thickness.

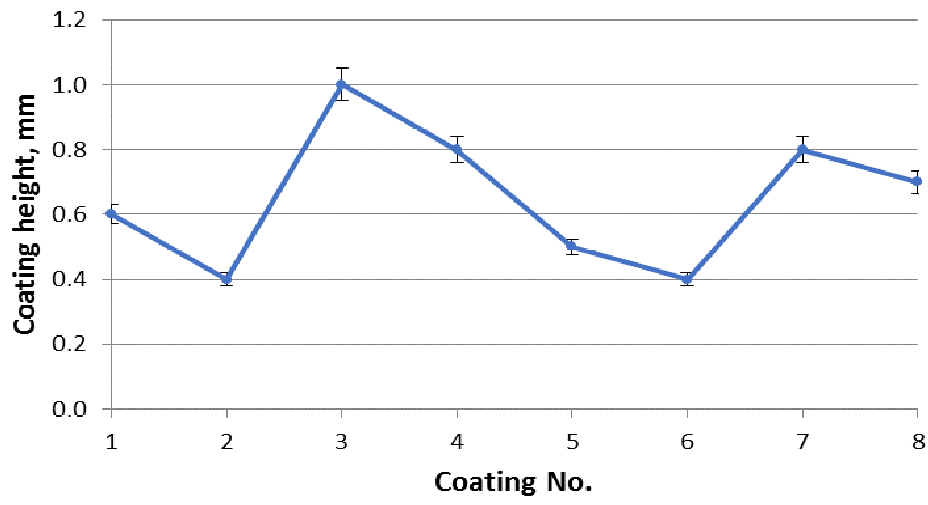

Fig. 6. Variation of coating thickness in as-clad condition

ANOVA for coating thickness: $D F$ - degree of freedom,

Table 4 $S S$ - sum of squares, $M S$ - mean squares

\begin{tabular}{|l|l|c|c|c|c|}
\hline Source & $\boldsymbol{D F}$ & $\boldsymbol{S S}$ & $\boldsymbol{M S}$ & $\boldsymbol{F}$ & $\boldsymbol{p}$ \\
\hline Model & 3 & 0.310 & 0.103 & 41.33 & 0.0018 \\
OR & 1 & 0.045 & 0.045 & 18.00 & 0.0132 \\
$V$ & 1 & 0.026 & 0.026 & 98.00 & 0.0006 \\
$f$ & 1 & 0.020 & 0.020 & 8.00 & 0.0474 \\
Residual & 4 & 0.010 & 0.003 & & \\
Total & 7 & 0.320 & & & \\
\hline
\end{tabular}

$F$-value 41.33 indicates that the relationship is statistically significant. $p$-values of less than 0.05 indicate that the overlap ratio $(O R)$, scanning speed $(V)$ and focal distance $(f)$ are all significant model terms. Especially the scanning speed was a dominant factor. Coefficient of determination $\left(R^{2}\right)$ was extremely high and equalled to 0.97 proves high correlation between the experimental and predicted results.

Additionally, empirical relationship between the coating thickness $(H)$ process parameters in coded factors is given in the following expression:

$$
H=0.75+0.01 O R-35 V-0.025 f \text {. }
$$


Equation (1) demonstrates that the scanning speed and focal distance have a negative effect onto the coating thickness. However, by increasing the percentage of $O R$ the coating thickness enlarges.

\section{Hardness}

Figure 7 shows a diagram of hardness in Rockwell $\mathrm{C}$ scale relative to the parameter set for two groups of coatings, which were grinded in two different directions. As it can be seen the hardness of the created coatings shows a little range of change, where the values vary from about 62 to $66 \mathrm{HRC}$. Direction of grinding generally does not have serious impact on the coating hardness, as the average value of this index for longitudinal grinding was $64.5 \mathrm{HRC}$, but in case of transverse grinding this value was $64.2 \mathrm{HRC}$. It was noticed that average highest values of hardness were achieved by processing with the laser beam defocused in plus direction, i.e. the focus plane below the treatable surface. Considering that the base material has hardness less than $20 \mathrm{HRC}(180 \mathrm{HB})$, it is seen that the produced coatings increase hardness of the sample more than three times.

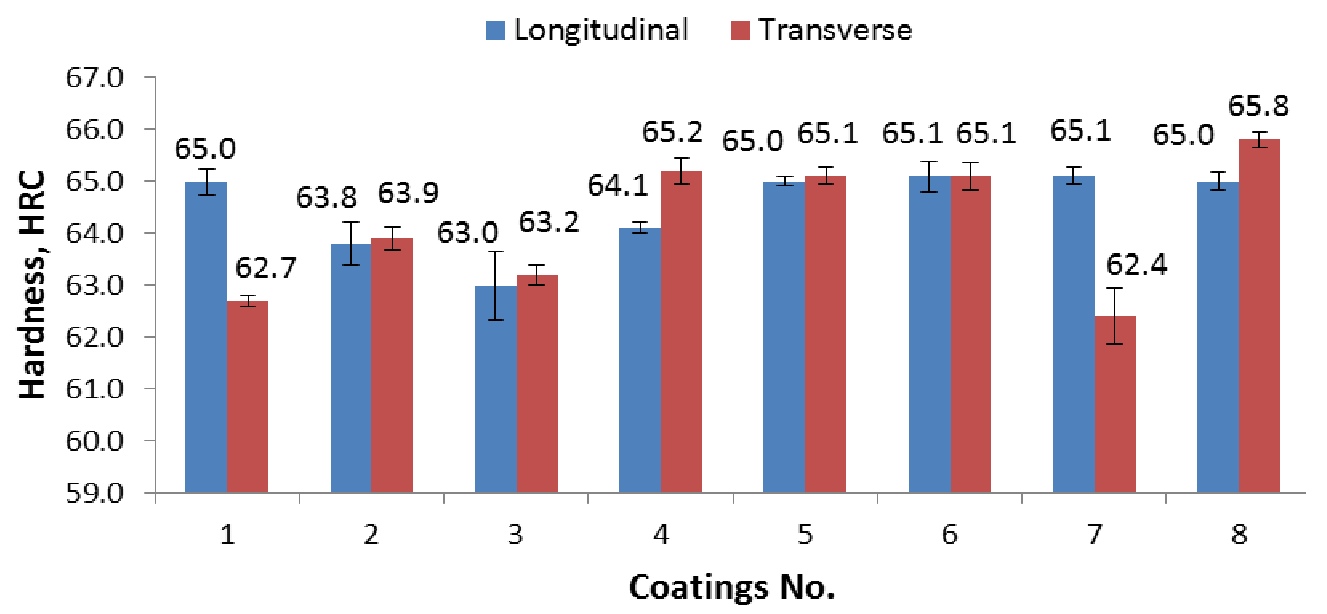

Fig. 7. Diagram of hardness of coatings (HRC) grinded in longitudinal and transverse directions

Table 5 shows ANOVA for hardness of coatings for two grinding directions. The poor $F$-values confirm that null hypothesis is true and this represents that the process parameter effect onto the coating hardness was insignificant.

Table 5

ANOVA for coating hardness

\begin{tabular}{|l|l|l|l|l|c||l|l|l|l|l|c|}
\hline \multicolumn{7}{|c||}{ Longitudinal grinding } & \multicolumn{7}{|c|}{ Transverse grinding } \\
\hline Source & $\boldsymbol{D F}$ & $\boldsymbol{S S}$ & $\boldsymbol{M S}$ & $\boldsymbol{F}$ & $\boldsymbol{p}$ & Source & $\boldsymbol{D F}$ & $\boldsymbol{S S}$ & $\boldsymbol{M S}$ & $\boldsymbol{F}$ & $\boldsymbol{p}$ \\
\hline Model & 3 & 2.674 & 0.891 & 2.103 & 0.243 & Model & 3 & 6.895 & 2.299 & 1.892 & 0.272 \\
OR & 1 & 0.001 & 0.001 & 0.003 & 0.963 & OR & 1 & 5.445 & 5.445 & 4.481 & 0.102 \\
$V$ & 1 & 0.361 & 0.361 & 0.853 & 0.408 & $V$ & 1 & 0.005 & 0.005 & 0.004 & 0.952 \\
$f$ & 1 & 2.311 & 2.311 & 5.454 & 0.080 & $f$ & 1 & 1.445 & 1.445 & 1.189 & 0.337 \\
Residual & 4 & 1.695 & 0.424 & & & Residual & 4 & 4.860 & 1.215 & & \\
Total & 7 & 4.369 & & & & Total & 7 & 11.755 & & & \\
\hline
\end{tabular}

\section{Coefficient of friction}

Coefficients of friction were measured on two coating groups by rotating the specimens with three different radiuses of sliding tracks. Wear rate of the testing ball was determined by measurements of ball damaged area after tests. These data are summarized and offered in the next Table 6 . For comparison, the coefficient of friction of substrate was 0.470 and wear area of the ball was $0.123 \mathrm{~mm}^{2}$.

Figure 8 demonstrates distributions of friction coefficients relative to the created coatings. The zero point corresponds to substrate data. As it can be seen in five cases the coatings were with larger value of the friction coefficient than this index for substrate. It was found that the coatings produced on a fifth set of parameters presented the best coefficients $(0.164$ for longitudinal and 0.210 for transverse directions), that was more than twice lower the values of substrate. This was achieved on 
the largest percentage of overlap $(50 \%)$, the highest speed $\left(0.02 \mathrm{~m} \cdot \mathrm{s}^{-1}\right)$ and by defocus the laser beam in plus direction (+2). Wear of the counter-body was well consistent with the coefficients of friction, showing high correlation of 0.86 . Overall the graphs have a very similar character of variation. Average coefficient measured for the longitudinal grinding direction was 0.4 and for the transverse direction the average value was 0.43 . This fact once again shows that the direction of grinding does not have significant effect. Actually, this along with the hardness results demonstrates isotropy of the coatings properties. This confirms that despite the laser cladding strategy, hardness and wear resistance will stay very similar.

Test results of friction coefficients

Table 6

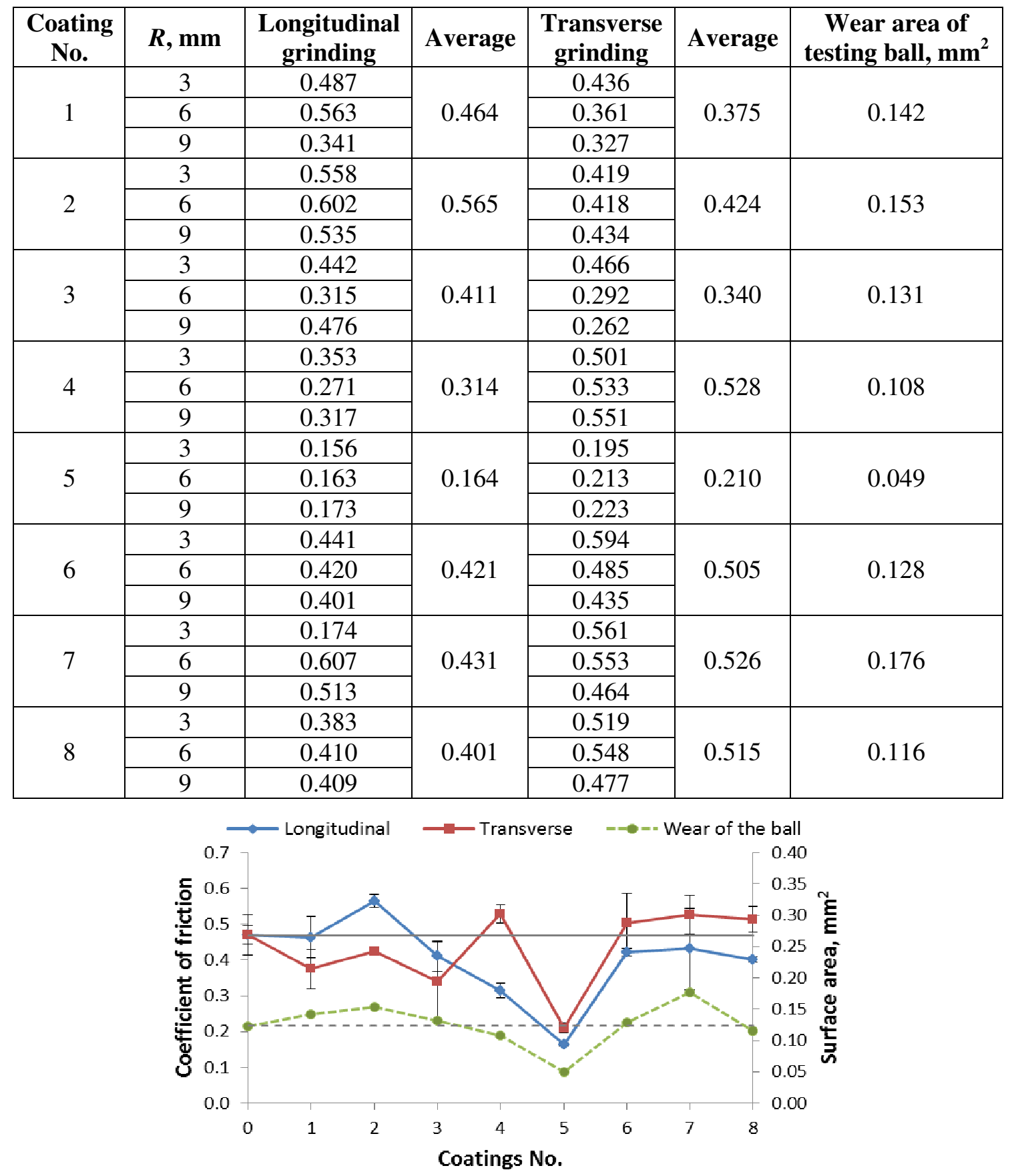

Fig. 8. Coefficients of friction for both grinding directions and surface area of counter-body wear 
In order to analyse the process parameter effect on the coefficient of friction ANOVA was also applied (Table 7), which represents that the $F$-values were very small and the $p$-values display high probability level to accept null hypothesis and this actually indicates statistical insignificance of relationships. Future studies with larger amount of samples are planned for full confirmation of the obtained results.

Table 7

ANOVA for the coefficient of friction

\begin{tabular}{|l|l|c|c|c|c||l|l|l|l|l|c|}
\hline \multicolumn{5}{|c||}{ Longitudinal grinding } & \multicolumn{7}{c|}{ Transverse grinding } \\
\hline Source & $\boldsymbol{D} \boldsymbol{F}$ & $\boldsymbol{S} \boldsymbol{S}$ & $\boldsymbol{M S}$ & $\boldsymbol{F}$ & $\boldsymbol{p}$ & Source & $\boldsymbol{D F}$ & $\boldsymbol{S S}$ & $\boldsymbol{M S}$ & $\boldsymbol{F}$ & $\boldsymbol{p}$ \\
\hline Model & 3 & 0.021 & 0.007 & 0.380 & 0.773 & Model & 3 & 0.054 & 0.018 & 1.973 & 0.260 \\
OR & 1 & 0.007 & 0.007 & 0.358 & 0.582 & OR & 1 & 0.034 & 0.034 & 3.690 & 0.127 \\
$V$ & 1 & 0.000 & 0.000 & 0.022 & 0.890 & $V$ & 1 & 0.020 & 0.020 & 2.122 & 0.219 \\
$f$ & 1 & 0.014 & 0.014 & 0.762 & 0.432 & $f$ & 1 & 0.001 & 0.001 & 0.108 & 0.760 \\
Residual & 4 & 0.075 & 0.019 & & & Residual & 4 & 0.037 & 0.009 & & \\
Total & 7 & 0.096 & & & & Total & 7 & 0.091 & & & \\
\hline
\end{tabular}

\section{Conclusions}

The high-speed tool steel coatings were deposited, in order to investigate the influence of the laser cladding process parameters including the laser overlap ratio, scanning speed and laser beam focus displacement as well as post-processing conditions. The generated coating quality was assessed by geometrical features and mechanical properties such as hardness and the coefficient of friction, which have been statistically analysed. The examination of the obtained results shows the following.

- The thickness of as-clad coatings varied from about 0.4 to $1 \mathrm{~mm}$, the maximal value corresponds to the lowest scanning speed and the smallest step of overlap.

- Combination of low scanning speed and defocus of the laser beam in minus direction leads to formation of pores.

- Hardness of the created coatings varies from about 62 to $66 \mathrm{HRC}$, which is more than three times higher in comparison to the base material.

- The optimal parameter set has been found by which the coefficient of friction was reduced more than twice $(0.16-0.21)$.

- Wear of the counter-body was well consistent with the coefficients of friction showing high correlation of 0.86 .

- The direction of grinding did not have significant effect onto hardness and the coefficient of friction, which points to isotropy of the coating tested properties. This means that both types of laser cladding strategies are applicable for creation of coatings onto cylindrical surface.

- ANOVA showed significant relationships between the process parameters and coating thickness, as a result an empirical model has been created.

- Statistical analysis represented that effect of the process parameters from the selected diapason on hardness and the friction coefficient was insignificant.

\section{Acknowledgements}

The authors gratefully acknowledge financial support from the company "Magistr Ltd" (Daugavpils, Latvia). Thanks also to Janis Lungevics for the assistance in measurement of hardness.

\section{References}

1. Schneider M.F. Laser cladding wth powder. PhD Thesis. University of Twente, Enschede, Netherlands, 1998. 177 p.

2. Toyserkani E. et al. Laser Cladding. New York: CRC Press LLC, 2005. 263 p.

3. Majumdar J. \& Manna I. Laser-Assisted Fabrication of Materials. Berlin: Springer, 2013. 485 p. 
4. Xue L. Laser consolidation: a rapid manufacturing process for making net-shape functional components. In Lawrence J., Pou J., Low D.K.Y. \& Toyserkani E. (eds): Advances in laser materials processing. UK: Woodhead Publishing Limited, 2010, pp. 492-534.

5. de Olivera U. et al. Analysis of coaxial laser cladding process conditions. Journal Surface \& Coatings Technology, 2005, No 197, pp. 127-136.

6. Hofman J.T. et al. FEM modeling and experimental verification for dilution control in laser cladding. Journal of Materials Processing Technology, 2011, No 211, pp. 187-196.

7. Santanu P. et al. Residual stress modeling of powder injection laser surface cladding for die repair applications. Proceedings of the ASME International Manufacturing Science and Engineering Conference "MSEC2014", June 9-13, 2014, Detroit, Michigan, USA, pp. 1-8.

8. Pleterski M. et al. Laser cladding of cold-work tool steel by pulse shaping. Journal of Material Science\&Technology, 2011, No 8, pp. 707-713.

9. Kattire P. et al. Experimental characterization of laser cladding of CPM 9V on H13 toll steel for die repair applications. Journal of Manufacturing Processes, 2015, No 20, pp. 492-499.

10. Pinkerton A.J. et al. Component repair using laser direct metal deposition. Proceedings of the Institution of Mechanical Engineers, Part B: Journal of Engineering Manufacture, UK, 2008, pp. 827-836.

11. Ocelík V. et al. Elimination of Start/Stop defects in laser cladding. Journal Surface \& Coatings Technology, 2012, No 206, pp. 2403-2409. 